\title{
A hydrothermal origin for the Shizilishan Sr-(Pb-Zn) deposit, China
}

\author{
QiaO-QIAO ZhU ${ }^{1,2}$, Nigel J. COOK ${ }^{2}$, GUI-QING XIE ${ }^{1}$, \\ CRistiana L. CiOBANU ${ }^{2}$ \\ ${ }^{1}$ Institute of Mineral Resources, CAGS, Beijing, 100037, \\ China (zhuqiaoqiao@cags.ac.cn, xieguiqing@cags.ac.cn) \\ 2 The University of Adelaide, S.A. 5005, Australia (nigel.cook \\ @adelaide.edu.au, cristiana.ciobanu@adelaide.edu.au)
}

Despite the high crustal abundance of strontium ( $\mathrm{Sr})$, celestine $\left(\mathrm{SrSO}_{4}\right)$, the dominant source of $\mathrm{Sr}$, is increasingly regarded as a critical mineral due to the lack of resources with sufficiently low $\mathrm{Ca}$ and $\mathrm{Ba}$ content to allow economic exploitation. This has prompted a resurgence of interest in understanding how $\mathrm{Sr}$ resources form. The largest known celestine deposits mostly occur within coastal carbonate and evaporite sequences and are classically interpreted to precipitate via seawater evaporation during transition from the carbonate- to gypsum-stage of evaporation [1]. Later models invoke epigenetic, early diagenetic replacement of carbonates and sulfates involving Sr-rich basinal fluids (e.g., [2]). Genetic relationships between $\mathrm{Sr}$ mineralization and magmatic-hydrothermal activity associated with igneous rocks are poorly documented in the literature.

The $\sim 5$ Mt Shizilishan Sr-(Pb-Zn) deposit, Eastern China, is located at the contact between a Lower Cretaceous ( 139 Ma) quartz diorite porphyry stock and Triassic evaporitebearing limestone/dolomite sequences [3]. Here we show that multiple generations of celestine, pyrite and marcasite can be recognized from micron-scale textures (BSE imaging), compositions (EPMA) and trace element signatures (LA-ICPMS). The complex growth zoning, dissolution and recrystallization textures displayed by celestine, as well as increased $\mathrm{Ba}$ content in later generations, are suggestive of evolving fluid compositions and physicochemical conditions. Relationships between pyrite and marcasite suggest a $\mathrm{pH}$ change from low to high. Geological relationships in the mine, alteration assemblages, deposit-scale zoning, analysis of ore textures, and the geochemical signatures preserved in ore and gangue minerals, allow us to interpret the Shizilishan deposit as an example of relatively low-temperature hydrothermal mineralization emplaced proximal to an intrusion. Such a genetic model, involving low-salinity fluids, may account for large celestine deposits if conditions of extensive water-rock interaction, protracted flow of fluids, moderate dissolved sulfate, and high $\mathrm{Sr} / \mathrm{Ba}$ ratios are met.

[1] de Brodtkorb et al. (1982) Mineral. Deposita 17, 423-436.

[2] García-Veigas et al. (2015) Ore Geol. Rev. 64, 187-199.

[3] Zhu et al. (2017) Acta Petrol. Sin. 33, 3484-3494. 